NBER WORKING PAPER SERIES

\title{
ENDOGENOUS CO-RESIDENCE AND PROGRAM INCIDENCE: SOUTH AFRICA'S OLD AGE PENSION
}

\author{
Amar Hamoudi \\ Duncan Thomas \\ Working Paper 19929 \\ http://www.nber.org/papers/w19929 \\ NATIONAL BUREAU OF ECONOMIC RESEARCH \\ 1050 Massachusetts Avenue \\ Cambridge, MA 02138 \\ February 2014
}

This research has been supported by NICHD grant R01-HD040245. We are grateful to Statistics South Africa, the Medical Research Council of South Africa, Macro International, and the University of Natal for providing us with access to the data. We have benefited from the comments of Angus Deaton, Arie Kapteyn, Dean Yang, Philip Cook, Christopher McKelvey, Sendhil Mullainathan, Marcos Rangel and Christopher Udry. The views expressed herein are those of the authors and do not necessarily reflect the views of the National Bureau of Economic Research.

NBER working papers are circulated for discussion and comment purposes. They have not been peerreviewed or been subject to the review by the NBER Board of Directors that accompanies official NBER publications.

(C) 2014 by Amar Hamoudi and Duncan Thomas. All rights reserved. Short sections of text, not to exceed two paragraphs, may be quoted without explicit permission provided that full credit, including (C) notice, is given to the source. 
Endogenous Co-residence and Program Incidence: South Africa’s Old Age Pension

Amar Hamoudi and Duncan Thomas

NBER Working Paper No. 19929

February 2014

JEL No. C81,I38,J12,O12

\begin{abstract}
$\underline{\text { ABSTRACT }}$
We investigate whether living arrangements respond to an arguably exogenous shift in the distribution of power in family economic decision-making. In the early 1990s, the South African Old Age Pension was expanded to cover most black South Africans above a sex-specific age cut-off resulting in a substantial increase in the income of older South Africans and potentially their say in the economic decisions of their families. Beneficiaries of the program are more likely to coreside with adults who have less human capital as measured by height and education. Since height and education are fixed for adults, this cannot be an effect of the pension income but reflects selective changes in living arrangements resulting from the pension. The findings highlight the endogeneity of living arrangements and illustrate the potential value of moving beyond theory and data that are confined to a spatially determined definition of the household.
\end{abstract}

\author{
Amar Hamoudi \\ Sanford School of Public Policy \\ Duke University \\ Durham NC 27708 \\ amar.hamoudi@duke.edu \\ Duncan Thomas \\ Department of Economics \\ Duke University \\ Box 90097 \\ Durham, NC 27708 \\ and NBER \\ d.thomas@duke.edu
}




\section{Introduction}

The literature is replete with efforts to measure welfare impacts of public programs implemented in a non-experimental setting; these require innovative approaches to isolate the program's causal impact on welfare. ${ }^{1}$ In this paper, we examine impacts on living arrangements of the South African Old Age Pension (OAP) — a generous, publicly financed cash transfer program. We present evidence that the program impacts family living arrangements in a manner that is selective on human capital characteristics. The findings shed light on an area of family economic behavior about which very little is known — namely, how living arrangements respond to changes in family income. The findings also have important implications for previous studies that have investigated the impact of the program on welfare indicators such as the human capital of children.

Studies have found, for example, that the South African OAP is positively associated with nutritional status of coresident young children as measured by height and weight (Case and Deaton, 1998; Duflo, 2000, 2003). The OAP is also positively associated with educational attainment of coresident older children (Edmonds, 2006), negatively associated with the market labor supply of coresident working-age men (Bertrand, Mullainathan, and Miller, 2003), and negatively associated with private remittances into the household (Jensen, 2004). One conclusion that emerges from these studies is that the public transfers have benefited individuals other than the primary recipient. However, this inference relies critically on the assumption that families' living arrangements — and therefore household composition - do not change in response to the OAP. If families do change their living arrangements, then time allocation and consumption choices of a household are a potentially misleading reflection of allocation decisions by the family. The broader point reflected in this case is that analyzing household rather than family data, without accounting for family-level responses, can lead to inappropriate conclusions about the impact of a program or resource. In an important paper about the OAP, Case and Deaton (1998) highlighted this point, but concluded that the data available at that time were "unlikely to be informative about this question."

When more data became available, studies documented that the demographic composition of the household did in fact respond to the OAP. For example, Posel, Fairburn, and Lund (2006) reported

\footnotetext{
${ }^{1}$ For discussions, see for example Moffitt (1991), Moffitt (2005), and Heckman, Lalonde, and Smith (1999).
} 
that adult coresidence is correlated with pension eligibility. Edmonds, Mammen, and Miller (2005) reported that households with pension-eligible women tended to have more young children, more women in their early twenties, and fewer women in their thirties. Ardington, Case, and Hosegood (2009) extended these analyses to examine change over time. They used two rounds of data collected by the Africa Center in rural KwaZulu-Natal. In those surveys, the household informant may name anyone - even nonresidents — as a "household member." A household's pension availability can change between waves if living arrangements change, if an elderly household member dies, or if an older member ages across the eligibility threshold. Ardington and coauthors related these changes in household composition to changes in whether adults are identified as "members" of the household, and where they reside. They found that after a household starts receiving pension income, prime age adults who coreside with the pensioner are less likely to be working, whereas those who reside outside of the rural area but are identified as "members" of the household are more likely to be working. Further, they reported that adults who have recently come to reside in a household tend to be older, less educated, and more likely to be unemployed, sick, or injured if that household receives pension income.

This paper extends the literature by reaching beyond documenting that living arrangements change with receipt of the OAP. Our results establish that prime age adults who coreside with pensioners are negatively selected in terms of their own level of human capital. The nature of this human capital selectivity is different for men relative to women, and for older versus younger prime-age adults. Adult human capital is measured by height and educational attainment — two indicators that are largely fixed by early adulthood. Associations between these fixed markers of human capital and receipt of the OAP cannot be attributed to the impact of pension income on human capital investments, since the program was implemented after the height and education of the adults were already determined. Rather, these associations result from selective changes in living arrangements in response to the OAP. This evidence provides important new insights into the impact of arguably exogenous changes in income in the hands of older adults on their own living arrangements and those of their families. It has important implications for interpreting evidence of the impact of the OAP on the human capital of coresident children and labor market outcomes of coresident adults.

For example, a clever study by Bertrand, Mullainathan, and Miller (2003) reports a negative association between prime-age adult labor supply and the pension income. In the absence of selective changes in living arrangements, it would be natural to infer from this pattern that the OAP causes a reallocation of adults' time from wage work to leisure, indicating that the benefits of the 
OAP are shared with these workers. On the other hand, Ardington and coauthors suggest that the pension income may have financed labor-related out-migration of household members. An economic model of family migration predicts that those members with higher expected wages in other locations would be more likely to be the ones who leave. Our finding that adults who coreside with pensioners tend to have lower levels of fixed human capital is consistent with this prediction, assuming that older South Africans are more likely to live in areas where the return to human capital is relatively low. It is plausible that the difference in human capital reflects changes in the pensioners' demand for services provided by coresident family members. The challenges in identifying the causal effects of the program are exacerbated if one further allows for the possibility of selective inmigration.

More generally, our results shed light on ways in which living arrangements reflect economic choices. This is an area that remains under-investigated in the literature. Means testing of the South African OAP takes into account only income and assets of the potential recipient him or herself. Thus, older adults have no incentive to change their living arrangements just to qualify for the pension income-for example, by not coresiding with higher income or wealthier family members. This feature of the program provides an opportunity to examine more nuanced aspects of family decisions over living arrangements. The economic character of living arrangements may be especially strong in South Africa, in part because of the legacy of apartheid. Historically, South African living arrangements have been fluid, with family members moving between multiple households. Migrant labor has played a significant role in determining family coresidence patterns. Many rural households depend for their income on remittances sent by family members working in urban or mining areas; married couples often live apart. It is common for family ties to remain strong across households, even when the households are separated by long distances or have been living apart for a long time. Since these are also features of life in most of the world, albeit magnified by the legacy of apartheid in South Africa, the dynamics explored here are likely to be relevant in many other contexts.

The next section provides a brief overview of the South African OAP, highlighting the features of the program used to empirically identify welfare effects in a non-experimental setting. Section 3 outlines the framework for our analysis. We sketch a model of decision making at the level of the extended family (as opposed to the single household, which we characterize as a subset of the family). In section 4, we provide the specifics of our empirical approach. Our empirical findings are in section 5. In concluding, we discuss what our results reveal about family economic decisions regarding living arrangements and the implications for empirical research. 


\section{The South African OAP}

The OAP is a generous public transfer of resources to older men and women in South Africa. It is non-contributory and the means test is sufficiently generous that the transfer is available to almost all of South Africa's majority black population when they reach the age of eligibility; for this population, receipt of pension income is unrelated to past work and savings decisions and is effectively determined by sex, age at last birthday, and take-up behavior.

The pension program was introduced in 1928 as an income supplement for elderly low income whites. In 1944, eligibility was extended to the "colored" and black population groups, with payment schedules dependent upon the recipient's race and location of residence. In 1965, differentiation based on residence was abolished but the racial gaps were maintained so that in 1975, for example, eligible whites received over R1200 (in 2004 prices), while coloreds received about R600 and blacks received less than R200. The racial gaps were reduced during the 1970s and 1980s and, with the fall of apartheid in the early 1990s, payments became race-blind. In 1993, the payment was set at R370 (R1200 in 2013 prices) and the payment remained approximately constant in real terms thereafter.

At the time of our study, all women age 60 and older and all men age 65 and older who satisfied a very generous income and assets means test were eligible for the pension. In 2004, for example, a single person was eligible for the grant if his or her monthly income was R1,502 or less and if the value of his or her assets was less than R266,400 (excluding owner-occupied housing). Only income or assets of the pension recipient are taken into consideration; few age-eligible blacks had assets (or income) that approach these levels. In the 2000 Income and Expenditure Survey, about 80\% of age eligible black women and about $75 \%$ of men reported receiving pension income. Although the size of the benefit is designed to vary according to the means of the recipient, the generosity of the means test meant that among those who reported any pension income in the year 2000, over 90\% reported receiving the maximum allowable payment of R740 (or about US\$120). This benefit level was very high since it is approximately equal to the median income of black 20-50 year old income earners in South Africa, and about the 70th percentile in rural areas at that time. More than 25\% of recipient black households in rural areas reported that the OAP was their only income source, and in urban areas it accounted for over $85 \%$ of total income for more than a quarter of recipient black households. The expected present discounted value of the pension was substantially greater for women than men, due to the age eligibility rule, and the fact that a man who survived to age 65 could expect to live an additional 7 years while a woman who survived to age 60 could expect to live 
an additional 10 years. In 2010, the criteria were changed so that both men and women became eligible at age 60 , but this change does not affect our study since our data come from many years before it was even considered a policy option.

\section{Conceptual Framework}

We examine how living arrangements adjust in response to the OAP. Building on prior research establishing an association between pension eligibility and changes in living arrangements (Posel, Fairburn, and Lund, 2006), we examine the nature of those adjustments, focusing on sorting of those who live with OAP recipients. The OAP does not only affect total household income; it also changes the distribution of income within a family. If a family is "unitary," the distributional effects should have no impact on economic behavior; only income effects would operate. However, in more general models of family decision-making, the distributional effects might be expected to give older adults more influence over collective family decisions and reorient family behavior towards allocations that the pensioner prefers. Such reallocation might involve adjustments to living arrangements. To illustrate this point, we incorporate the "technology" of home production into a simple model of family optimization.

Suppose a family can transfer goods at relatively low cost among its members, regardless of coresidence patterns (for example, through cash remittances) but the lowest cost way to transfer services provided by a family member is through the adjustment of living arrangements. If the pension income increases the pensioner's demand for relatively labor intensive home-produced services, then it may be efficient for those services to be provided by family members who have comparative advantage in in-home labor - that is, those whose market wages are low relative to other family members. Furthermore, costs of providing those services may be minimized when these family members coreside with the pensioner - for example, personal care may be easier if the caregiver does not incur the costs of travel to the recipient's home. An implication of this model is that the pension would increase the probability that the pensioner co-resides with adult family members who have lower human capital.

More generally, consider a family in which each member has distinct preferences, defined over the consumption of leisure and an arbitrary number of home-produced goods and services. These goods 
and services are produced using market inputs and the time and human capital of household members. Transaction costs are lower for market inputs than for labor, which is more easily transferred between households via the adjustment of living arrangements. ${ }^{2}$ The family would allocate individuals and transferable inputs across households and also leisure and consumption across individuals in order to optimize some function which aggregates individual welfare, taking into account time, resource, and "technological" constraints. The "technology" of household production involves combining market inputs (say, food) with the time and skills of family members (say, time and effort spent cooking). In such a model, the market-inputs constraint can be represented as common to the family_all income, regardless of where it accrues, may be used to purchase market inputs, regardless of where they are employed. However, the time and "technological" constraints might be represented as specific to each household - in the limiting case, where transaction costs are high enough, then final ${ }^{3}$ goods and services can be consumed only in the household where they are produced. In such a model, if the partition of individual members into households is represented as a choice, then the equilibrium assignment will almost surely be related to individual and family characteristics — many of which, such as preferences, are not straightforward to measure. Furthermore, theory is silent on relationships between the equilibrium assignment of individuals to households and individual characteristics without strong assumptions about the family welfare function, individual preferences, and the "technologies" of home production. This a priori ambiguity motivates our empirical investigation of characteristics of adults who co-reside with pensioners.

\section{Data and Empirical Strategy}

Many studies have measured intent to treat (ITT) effects of the OAP by estimating regression discontinuities in outcomes of interest around the age-eligibility thresholds. However, receipt of the pension is not solely a function of eligibility; eligible individuals must apply and establish their age. In spite of its generosity, take-up among those who are eligible is not universal. Table 1 displays

\footnotetext{
${ }^{2}$ The model can be generalized to incorporate more subtle distinctions between purchased goods and home-produced services. The essential insights for this paper are not qualitatively changed. For example, transport costs for goods and services can be included as a function of the spatial distribution of households. The model would need to take into account not only the (endogenous) assignment of individuals to households, but also the (endogenous) geographical location of each household.

3We use "final" here in the sense originally described by Becker (1965).
} 
take-up rates using data from the 2000 Income and Expenditure Survey which is a populationrepresentative household budget survey designed to calculate weights for the consumer price index. Table 1 indicates a large jump in take-up around the age at which men and women became ageeligible for the pension. However, take up continued to rise for another five to ten years beyond the eligibility threshold, and then plateaued at around 90\% among blacks.

With incomplete take-up, under the assumption that effects are the same for those who do and do not take-up the OAP, the ITT estimate, rescaled by the fraction of takers, provides an estimate of the local average treatment effect of the OAP. However, if those who take up the program and those who do not differ in ways that are related to outcomes of interest but not controlled in the models, a more structural approach to estimation is needed. To this end, we use an instrumental variables specification to first model the take-up choice, and in the second stage we use the predicted probability of take-up to estimate the relationship between program participation and outcomes of interest. We use age-eligibility as our instrument in the take-up regression; it will be valid as long as there are no other discrete changes that occur at age 60 for women and age 65 for men that are also related to outcomes of interest. The strength of the instrument is apparent in Table 1. For example, among black women, take-up increases by 52 percentage points for those who are just age eligible relative to those who are almost age eligible.

This approach assumes there are no relevant behavioral responses to the timing of eligibility. For example, if families with older adults spend down assets in anticipation of the future pension or save less than they would without the pension, then this approach (and all of the similar approaches used in the literature on the OAP) would likely yield an attenuated estimate of the relationship of the pension with the outcome of interest. ${ }^{4}$

We use data from the 1998 Demographic and Health Survey (DHS) to analyze whether and how adult coresidents are selected in terms of their height and education. Since both of these indicators of human capital are fixed in adulthood, and thus at the time of OAP receipt, we interpret

${ }^{4}$ Edmonds (2006) explicitly conceptualizes the pension as a component of expected permanent income, and examines whether the timing of its arrival affects family economic behavior. In this sense, smooth variation around the age eligibility threshold represents a counterfactual in his analysis. 
associations between adult human capital and OAP receipt in a household as indicative of selective patterns of co-residence with pensioners.

The 1998 DHS is well suited for these analyses. The survey is representative of the population of South Africa and was conducted soon after the OAP had been extended to blacks across the entire country. The survey records detailed demographic information on all adults age 15 and older, including education. In addition, a randomly selected subsample of $40 \%$ of adult respondents completed a health assessment which included measurement of height. We examine how pension receipt covaries with height (in centimeters) and education (measured as years of completed schooling) of adult respondents aged 20 to 55 years.

In regression equation [1], human capital of adult $i$ in household $h\left(\theta_{i b}\right)$ is a function of household pension receipt $\left(R_{b}\right)$ which is appropriately treated as endogenous because take-up is potentially related to unobserved characteristics $\left(\varepsilon_{i h)}\right.$, such as tastes of household members.

$$
\theta_{i h}=\beta_{0}+R_{h} \beta_{1}+C_{h} \beta_{2}+W_{h} \beta_{3}+X_{i h} \beta_{4}+\varepsilon_{i h}
$$

Our instrument for pension receipt is a dummy variable that takes the value of 1 if there is at least one household resident who is eligible for the pension based on age and sex; the value is 0 otherwise. In order to isolate the impact of coresiding with a pensioner, it is important to also control household composition. To this end, regression models control for household size and composition $\left(C_{b}\right)$ by including the number of men and, separately, the number of women in each of 5 age-specific groups-0-19, 20-24, 25-54, 55-74, and 75 and older. This ten-dimensional vector flexibly controls household size and composition while preserving enough variation to identify the effects of pension receipt. It is important to note that it is possible to allow considerably more flexibility in composition controls, and that our main conclusions are robust to a broad set of specifications of household composition controls. ${ }^{5}$

${ }^{5}$ We have experimented with specifications that include both fewer age groups and more age groups, including one that controls the number of male and female household members in each of 16 gender-specific age groups $0-2,3-7,8-12$, $13-17,18-22, \ldots 53-57,58-62,63-67,68-72, \geq 73)$. We have also experimented with models that control the number of male adults, female adults, male children $($ age $<15)$ and female children. None of our conclusions depends on how demographic composition is controlled. The models in the table strike a balance between controlling demographic 
The models control individual and household characteristics that are likely to be associated with adult human capital. Since the DHS does not include detailed information on income or consumption, we control for heterogeneity in socioeconomic status using 19 indicator variables capturing information on household wealth, $W_{b}{ }^{6}$ The vector $X_{i b}$ captures differences in human capital across birth cohorts - it includes an indicator for whether individual $i$ is in each age band 20$24,25-29, \ldots, 50-55$. All models are stratified by sex. Standard errors are computed using a clustered sandwich estimator of the variance-covariance matrix in order to be robust to heteroskedasticity and to take into account the fact that pension receipt is measured at the household level.

\section{Results and Discussion}

\subsection{Adult buman capital: education and height}

Panel A of Table 2 displays estimates of the relationship between each measure of adult human capital and whether anyone in the household received a pension-regardless of the sex of the recipient. Average education and height of sample respondents is in panel $\mathrm{C}$ and sample sizes are in panel D. The instrument, the presence of a household member who is age-eligible for the OAP, is a powerful predictor of pension receipt. This is displayed in Panel E which reports F statistics for the significance of the identifying instruments in each first stage regression .

Instrumental variable estimates of regression model [1] for all coresident adults age 20-55 are in row 1 of Panel A, for younger adults (20-30) in row 2 and older adults (31-55) in row 3. As shown in the first column and first row, a man aged 20-55 who lives with a pension recipient has completed 1.02 fewer years of schooling than a similar man who lives in a household with the same demographic composition except that it does not include a pensioner. This difference is statistically significant, and substantial; it amounts to almost $12 \%$ of the total average education for men in this age group. The gap in educational attainment is also statistically significant and substantial among younger men (age 20-30) and also among younger women. Turning to height, women who live with at least one

composition in a flexible way and over-controlling. We have also experimented with specifications that include flexible splines for ages of the oldest male and female household members. Conclusions drawn from those models are substantively the same as the results we report.

${ }^{6}$ Seven indicator variables identify whether the household owns at least one car, motorcycle, bicycle, refrigerator, television, radio and whether the household has electricity. The rest of the $W_{b}$ vector consists of indicator variables for the type of floor and type of wall (six indicator variables each). 
pensioner are shorter than women who do not. For all women, the difference is $2.76 \mathrm{~cm}$ and statistically significant. The gap translates to more than a third of a standard deviation in the distribution of the height of adult women in the sample. The gap is about the same for older women and slightly smaller for younger women, but neither is statistically significant. Height of a man is not significantly associated with whether he coresides with a pension recipient. ${ }^{7}$

Given the substantial differences by sex in the return to human capital in the labor market and the likely differences in productivity in the home, there are good reasons to examine coresidence choices and human capital of men and women separately. Moreover, both height and education are interpreted as markers of human capital and, in the absence of a widely-accepted marker of quality of human capital, we have chosen to explore the relationship between coresidence with a pension and each of these markers. While it is informative to investigate whether these relationships vary by age of the adult, this empirical approach raises potential concerns regarding multiple inference (Hochberg and Tahmane, 1987). We have therefore estimated all the models taking this concern into account. Stratifying the analyses by sex, we have used resampling techniques to adjust critical values in light of multiple testing (Efron and Tibshirani, 1993). Appendix Table 1 reports the IV coefficient, absolute value of the asymptotic Z-test statistic for a null hypothesis that the IV coefficient is zero, and the associated $p$-values (using resampling methods) in columns 1, 2 and 3 respectively. Two approaches have been adopted to take into account multiple testing, separating the models for men from those for women. First, for each gender, we have used a free step-down resampling approach (Westfall and Young, 1993) which has been shown to be more powerful than the Bonferroni correction (shown in column 4). The unadjusted $p$-values (in column 3) for the three significant coefficients in the education models are 0.003 for all men, 0.009 for younger men and 0.024 for younger women. The $p$-values that take into account multiple inference (in column 4) are 0.015, 0.040 and 0.107 , respectively. In the height models, the only significant case is for all women. The unadjusted $p$-value is 0.017 and the adjusted $p$-value is 0.084 . This adjustment is known to be very conservative and is thought to be appropriate in cases in which the cost of false rejection is high

\footnotetext{
${ }^{7}$ Data were collected in 1998 and for the vast majority of the sample, height and education were determined before the OAP was expanded in 1993. However, some of the youngest respondents may not have completed their education or attained their adult stature at that time. To address this concern, the models have been re-estimated restricting the sample to those age 25 or older in 1998. None of the results in Table 2 is affected in terms of sign, significance or magnitude (up to the first decimal place).
} 
(Anderson, 2008). Hypothesis tests based on an alternative, more powerful approach are reported in column 5; this approach takes into account multiple testing, controls the false discovery rate and reduces the penalty associated with additional tests (Benjamini and Hochberg, 2001). The $p$-values are $0.017,0.027$ and 0.073 for the three education models and 0.073 for the height model discussed above. We conclude that the results for men cannot be attributed to multiple testing and the results for women are unlikely to be due to multiple testing, at least at a 10\% size of test.

Returning to the substantive results, several mechanisms potentially explain the relationship between adult human capital and coresidence with a pensioner. With enhanced bargaining power, the pensioner may shift family consumption toward home-produced services like personal care. Market wages are strongly correlated with human capital generally, and education and height, specifically (Case and Paxson, 2008; Kerr and Teal, 2012; Mwabu and Schultz, 1998; Lam, 1999; Strauss and Thomas, 2008; Thomas and Strauss, 1997). Thus, individuals with a comparative advantage in producing home-produced services for the pensioner would likely be those individuals with less human capital. In that case, the shift in family demands would result in these family members coresiding with the pensioner. The pension income could also cause a shift in family time allocation which involves relatively higher human capital adults living apart from the pensioner (see Ardington, Case, and Hosegood, 2009 and Posel, Fairburn, and Lund, 2006). While it is not possible to distinguish these hypotheses using the DHS, the evidence presented here has clear and important implications. In response to a rise and redistribution of income (and presumably a redistribution of bargaining power) in the family, living arrangements change in a manner that is selective on human capital; this selectivity is observed even after controlling for household demographic composition and individual age and sex. In addition to providing insights into family behavior, this evidence indicates the importance of taking into account behavioral responses, such as changes in living arrangements, when evaluating public programs. See Ardington et al (2012) for recent evidence investigating this question.

Studies have concluded that how pension income is spent depends on the sex of the pensioner (for example, Duflo, 2003). Panel B of Table 2 explores whether selection varies with the sex of the pension recipient, separating households that have only female pension recipients (in row 1), only male recipients (in row 2), and both male and female recipients (in row 3). There is more negative selection on education in households with only male recipients. It is possible that these adults have comparative advantage working in a family enterprise and their skills complement those of the male pensioner, or that they have comparative advantage in home production of the services that male 
pensioners specifically demand, or that they have similar tastes for household public goods as male pensioners. In all of these cases, it would be efficient for them to live with the male pensioner.

Given the evidence that adults who live with pensioners are negatively selected in terms of their human capital, we turn next to examine the human capital of children who live with pensioners.

\subsection{Child buman capital: education}

Since the DHS does not measure physical health of children, we examine the relationship between living arrangements and educational attainment of children (age 6 to 14). These results are shown in Table 3. The regression models parallel equation [1]. Education, $\theta_{i b}$, is measured as the level and grade in which child $i$ is currently enrolled (or was last enrolled) translated into the number of years of schooling necessary to attain that grade. Models are estimated separately for boys and girls; age controls, $X_{i h}$, are specified as a dummy variable for each year of age. Receipt of a pension is treated as endogenous with the presence of an age-eligible resident in the household as the instrument. Household composition is specified as the number of household members in the same 10 age-andsex-specific groups used in the models of adult human capital discussed in section 5.1.

As shown in Panel A of the table, 6-14 year old boys who live with a pensioner are 0.36 years behind in their schooling compared with boys of the same age who live in households of similar demographic composition except without a pensioner. This gap is significant and slightly larger for younger boys (6-12) than for older boys (13-14). There is no difference in the schooling of girls who do and do not live with a pensioner. We do observe a large (albeit statistically insignificant) difference for 13-14 year old girls; these girls are more likely to be involved in producing services for which demand may increase with pension income.

The third column of each panel in the table displays the difference in the pension-education relationship for boys compared with girls. Living with a pensioner is better for 6-12 year old girls than for 6-12 year old boys, by almost a half-year. One interpretation of this evidence is that pension income benefits girls more than boys. This is the interpretation given to parallel evidence on child height by Case and Deaton (1998) and by Duflo (2003). Applying this interpretation to Table 3, however, would not imply that pension income is used to invest in the schooling of girls but rather that pension income causes boys to quit school. Duflo notes that living with a grandmother is associated with taller daughters. We find no evidence that the relationship between education of a child and coresidence with a pension recipient varies significantly with the sex of the pensioner. 
An alternative interpretation of the results in Panel A of Table 3 is that pension-related changes in living arrangements may underlie the observed association. Endogenous sorting of family members may arise for several reasons. It may be that for some children, the production of human capital is relatively more intensive in family members' labor. From the point of view of the family, some children may acquire skills more efficiently in school, while others might acquire them more efficiently under the guidance of a grandparent. In that case, if children's human capital is a normal good in the family welfare function, the pension will increase the likelihood that these differently endowed children will be sorted into different households. In that case, coresidence with a pensioner would be correlated with human capital outcomes along the lines observed in panel A of Table 3.

However, it is also possible that the sorting of children to households may result from the sorting of their parents. As shown in Table 2, adults who coreside with a pensioner tend to have lower levels of human capital. Parental human capital is a powerful predictor of child human capital (Lam, 1999; Strauss and Thomas, 1990, Thomas, 1996); in a society where almost all children live with a parent, the sorting of parents would straightforwardly generate associations like those observed in Panel A of Table 3. In South Africa, the context is more complex; a substantial (and selected) fraction of children do not coreside with parents; in our sample, about 35\% of 6-14 year old children live apart from their parents. This is in keeping with a well-documented pattern of child fostering (see for example Zimmerman, 2003).

Since parental human capital is reported in the DHS only for children living with their parents, it is difficult to test directly the role played by sorting of parents in driving the associations observed in Panel A of Table 3. The issue is explored by extending model [1] to include controls for whether the child lives with his or her mother and/or a pensioner. Recall that higher human capital women are less likely to live with pensioners. The children of these women are also likely to have higher levels of human capital. Further, if these women also tend to live with their best-endowed children (for example, if they are more likely to be working and living in areas where more high-quality schooling is available), then the highest human capital children will be more likely to live with their mothers and less likely to live with the pension recipient. In that case, children who live with their mothers, and whose mothers in turn are (negatively) selected into living with a pensioner, would have the lowest levels of human capital.

The evidence, displayed in Panel B of Table 3, is consistent with this hypothesis. Children living with their mothers are "protected" in the sense that they tend to have higher levels of human capital than 
those who live apart from their mothers. However, this "protective" effect is more than offset if a boy and his mother are living with a pensioner. The interaction effect, in the third row of the panel, is significant for males and larger for older children.

Living arrangements that are selective on human capital are not the only mechanisms that can explain these results. However, if the patterns in Panel A are interpreted as evidence that pension income increases investment in the human capital of some children relative to others, we would expect those differences to be reinforced when the mother is present in the pension-receiving household. In fact, the evidence is in the opposite direction, indicating that children who coreside with their mothers and a pension recipient have lower levels of schooling than those who coreside with only a pension recipient. A more plausible interpretation of the evidence is that it reflects, at least in part, endogenous sorting of household members driven by comparative advantage.

\section{Conclusion}

The South African OAP is a generous cash transfer which provides each older black man and woman with a guaranteed income that places him or her around the median of the income distribution among the country's black population. Eligibility for the transfer is determined primarily by age and sex. In a series of creative studies that explore decision-making within households, the OAP (or eligibility for it) has been treated as a source of exogenous variation in income. Some authors of those studies have noted that interpretation of their results depends on assumptions about how living arrangements respond to the OAP and have recommended empirical investigation of these assumptions. This paper takes up that challenge.

We find that the pension income re-sorts adults in the extended family based on fixed human capital characteristics (educational attainment and, to a lesser extent, height). Furthermore, the specific patterns of sorting point to potential roles that living arrangements may play in the extended family's allocation of final goods and services. Specifically, one interpretation of our findings is that as older adults become eligible for the OAP, they are able to shift the extended family's demand toward goods and services that are more intensive in domestic labor. This is most efficiently provided by those adult family members whose market value of time is relatively low; co-locating these adults with the pensioner is a potentially efficient way of meeting the new pattern of demand.

These findings have important implications not only for the interpretation of evidence on the impact of the OAP, but also for evaluations of other cash and in-kind transfer programs that draw 
on household-level data. If family members are sorted into households on the basis of characteristics that are not fully controlled, then comparisons of outcomes between eligible and non-eligible (or recipient and non-recipient) households capture not only the direct effects of the transfer, but also the effects of changes in living arrangements induced by the transfer.

In the specific case of the OAP, even if human capital of co-resident adults were controlled in empirical models, it is unlikely that those observed markers of selection will fully address concerns regarding the confounding impact of changes in living arrangements. Thus, attributing estimated associations between receipt of the OAP and outcomes of adults and children to the impact of exogenous variation in income may be substantially misleading.

To take an example of another cash transfer program, PROGRESA/Oportunidades in Mexico conditions receipt of income on continuously residing in the same household. Those programs reduce the incentive for an individual to leave the household or migrate out of the community in search of better prospects. This has the potential to substantially complicate interpretation of comparisons between "treated" and "untreated" households, since these comparisons do not take the endogeneity of living arrangements into account.

More generally, this research highlights the likely value to science and policy of moving beyond theory and data that is bound by the confines of a spatially-defined household to a broader conceptualization of the networks that play an important role in decisions about family life. Systematically including non-co-resident family members in both the design of data collection activities and in models that evaluate programs is likely to be a profitable next step for inquiry into individual and family behaviors. 


\section{References}

Anderson, Michael. 2008. "Multiple Inference and Gender Differences in the Effects of Early Intervention: A Re-evaluation of the Abcederian, Perry Preschool and Early Training projects." Journal of the American Statistical Association, 103.484:1481-95.

Ardington, Cally, Anne Case, and Victoria Hosegood. 2009. "Labor Supply Responses to Large Social Transfers: Longitudinal evidence from South Africa.” American Economic Journal: Applied Economics, 1(1): 22-48.

Ardington, Cally, Anne Case, David Lam, Murray Leibbrandt and Alicia Menendez. 2012. "Social Protection and Labor Market Outcomes in South Africa: Employment and youth transitions to the marketplace." Mimeo.

Becker, Gary S. 1965. “A Theory on the Allocation of Time," The Economic Journal, 75(299):493-517.

Benjamini, Yoav and Yosef Hochberg. 2001. "The Control of the False Discovery Rate in Multiple Testing under Dependency." The Annals of Statistics, 29(4):1165-88.

Bertrand, Marianne, Sendhil Mullainathan, and Douglas Miller. 2003. "Public Policy and Extended Families: Evidence from pensions in South Africa." World Bank Economic Review, 17(1):27-50.

Case, Anne, and Angus Deaton. 1998. "Large Cash Transfers to the Elderly in South Africa." Economic Journal, 108(450):1330-61.

Case, Anne, and Christina Paxson. 2008. "Stature and Status: Height, ability, and labor market outcomes." Journal of Political Economy, 116(3):499-532.

Duflo, Esther. 2000. "Child Health and Household Resources: Evidence from the South African Old Age Pension Program.” American Economic Review: Papers and Proceedings, 90(2):393-398.

Duflo, Esther. 2003. "Grandmothers and Granddaughters: Old-Age Pensions and intrahousehold allocation in South Africa." World Bank Economic Review, 17(1):1-25.

Edmonds, Eric. 2006 "Child Labor and Schooling Responses to Anticipated Income in South Africa." Journal of Development Economics, 81:386-414

Edmonds, Eric, Kristin Mammen, and Douglas L. Miller. 2005. "Re-arranging the Family? Income support and elderly living arrangements in a low income country." Journal of Human Resources, 40(1):186-207.

Efron, Bradley and Robert. Tibshirani. 1993. An Introduction to the Bootstrap. Boca Raton: Chapman and Hall/CRC.

Heckman, James J., Robert J. Lalonde, and Jeffrey A. Smith. 1999. "The Economics and Econometrics of Active Labor Market Programs." In Handbook of Labor Economics, vol. 3 A, ed. Orley Ashenfelter and David Card, 1865-2097. New York: Elsevier Science.

Hochberg, Yosef and Ajit Tamhane. 1987. Multiple Comparison Procedures. New York: Wiley. 
Jensen, Robert T. 2004. "Do Private Transfers Displace the Benefits of Public Transfers? Evidence from South Africa." Journal of Public Economics, 88(1):89-112.

Kerr, Andrew and Francis Teal. 2012. "The Determinants of Earnings Inequalities: Panel data evidence from South Africa.” CASE working paper, Oxford University.

Lam, David. 1999. "Generating Extreme Inequality: Schooling, earnings, and intergenerational transmission of human capital in South Africa and Brazil." mimeo, University of Michigan.

Moffitt, Robert. 1991. "Program Evaluation with Non-Experimental Data." Evaluation Review, 15(3):291-314.

Moffitt, Robert. 2005. "Remarks on the Analysis of Causal Relationships in Population Research." Demography, 42(1):91-108

Mwabu, Germano and T. Paul Schultz, 1998, "Wage Premia for Education and Location by Gender and Race in South Africa." Yale Economic Growth Center Discussion Paper 785.

Posel, Dorrit, James A. Fairburn and Frances Lund. 2006. "Labour migration and households: A reconsideration of the effects of the social pension on labor supply in South Africa." Economic Modelling, 23(5):836-853.

Strauss, John and Duncan Thomas. 1990. "Child Survival, Height for Age and Household Characteristics in Brazil.” Journal of Development Economics, 33(2):197-234.

Strauss, John and Duncan Thomas. 2008. "Health Over the Life Course" in T. Paul Schultz and John Strauss, (eds.), Handbook of Development Economics Volume 4, 3375-3474.

Thomas, Duncan. 1996. "Education across generations in South Africa", American Economic Review, Papers and Proceedings, 86.2:2330-34.

Thomas, Duncan and John Strauss. 1997. "Health and Wages: Evidence on men and women in urban Brazil.” Journal of Econometrics, 77:159-185.

Westfall, Peter and Stanley Young. 1993. Resampling-based Multiple Testing. New York: Wiley.

Zimmerman, Fredrick J. 2003. "Cinderella Goes to School: The effects of child fostering on school enrollment in South Africa." Journal of Human Resources, 38(3):557-590. 
Table 1: Pension eligibility and pension receipt

Percentage of individuals in each age group who receive an old age pension

\begin{tabular}{ccccc}
\hline \multirow{2}{*}{ Age group } & \multicolumn{2}{c}{$\underline{\text { Blacks }}$} & \multicolumn{2}{c}{ Non-Blacks } \\
& $\begin{array}{c}\text { Women } \\
{[1]}\end{array}$ & $\begin{array}{c}\text { Men } \\
{[2]}\end{array}$ & $\begin{array}{c}\text { Women } \\
{[3]}\end{array}$ & $\begin{array}{c}\text { Men } \\
{[4]}\end{array}$ \\
\hline $50-54$ & 2 & 2 & 1 & 2 \\
$55-59$ & 8 & 3 & 6 & 4 \\
$60-64$ & 60 & 15 & 40 & 17 \\
$65-69$ & 85 & 61 & 55 & 36 \\
$70-74$ & 89 & 82 & 61 & 39 \\
$75-79$ & 90 & 84 & 55 & 40 \\
$80-84$ & 93 & 93 & 56 & 36 \\
$85+$ & 90 & 89 & 56 & 51 \\
\hline \hline
\end{tabular}

Notes: Data are drawn from the 2000 Income and Expenditure Survey. Percentages are weighted to be population-representative. 
Table 2: Human capital of adults and presence of a co-resident pension recipient

\begin{tabular}{|c|c|c|c|c|}
\hline \multirow[t]{2}{*}{ Dependent variable: } & \multicolumn{2}{|c|}{ Education (years) } & \multicolumn{2}{|c|}{ Height $(\mathrm{cm})$} \\
\hline & $\begin{array}{c}\text { Men } \\
{[1]} \\
\end{array}$ & $\begin{array}{c}\text { Women } \\
{[2]}\end{array}$ & $\begin{array}{c}\text { Men } \\
{[3]} \\
\end{array}$ & $\begin{array}{c}\text { Women } \\
{[4]}\end{array}$ \\
\hline \multicolumn{5}{|l|}{ A. Any pension recipient(s) in household } \\
\hline \multirow[t]{2}{*}{1 All co-resident adults (Age $20-55$ years) } & -1.02 & -0.47 & 0.78 & -2.75 \\
\hline & {$[0.34]$} & [0.32] & [1.43] & {$[1.17]$} \\
\hline \multirow[t]{2}{*}{2 Younger co-resident adults (20-30 years) } & -1.17 & -0.85 & 1.50 & -2.09 \\
\hline & {$[0.45]$} & [0.38] & [1.85] & {$[1.48]$} \\
\hline \multirow[t]{2}{*}{3 Older co-resident adults ( $31-55$ years) } & -0.87 & -0.19 & -0.14 & -2.86 \\
\hline & {$[0.48]$} & {$[0.48]$} & {$[2.24]$} & [1.78] \\
\hline \multicolumn{5}{|l|}{ B. Pension recipient distinguished by gender } \\
\hline \multicolumn{5}{|l|}{ Sample: All co-residents adult age $20-55$ years } \\
\hline \multirow[t]{2}{*}{1 Female recipient(s) only } & -0.81 & -0.31 & 0.16 & -2.69 \\
\hline & [0.38] & {$[0.34]$} & {$[1.52]$} & {$[1.41]$} \\
\hline \multirow[t]{2}{*}{2 Male recipient(s) only } & -1.85 & -0.86 & 2.63 & -2.64 \\
\hline & {$[0.67]$} & [0.54] & {$[2.40]$} & {$[1.67]$} \\
\hline \multirow[t]{2}{*}{3 Both male and female recipients } & -1.03 & 0.13 & -1.12 & -1.41 \\
\hline & {$[0.58]$} & [0.53] & [2.63] & [2.26] \\
\hline \multicolumn{5}{|l|}{ C. Average of dependent variable } \\
\hline $20-55$ years of age & 8.6 years & 8.1 years & $168.8 \mathrm{~cm}$ & $158.4 \mathrm{~cm}$ \\
\hline $20-30$ years of age & 9.5 years & 9.6 years & $168.7 \mathrm{~cm}$ & $158.5 \mathrm{~cm}$ \\
\hline $31-55$ years of age & 7.9 years & 7.2 years & $168.8 \mathrm{~cm}$ & $158.3 \mathrm{~cm}$ \\
\hline \multicolumn{5}{|l|}{ D. Sample sizes: Number of co-resident adults } \\
\hline $20-55$ years of age & 9,258 & 11,349 & 3,559 & 4,990 \\
\hline $20-30$ years of age & 3,981 & 4,389 & 1,456 & 1,895 \\
\hline $31-55$ years of age & 5,277 & 6,960 & 2,103 & 3,095 \\
\hline \multicolumn{5}{|l|}{ E. First stage F statistic on identifying instruments } \\
\hline A.1 All co-resident adults (Age $20-55$ years) & 429.4 & 436.7 & 142.2 & 181.2 \\
\hline A. 2 Younger co-resident adults (20-30 years) & 250.9 & 272.9 & 70.1 & 97.3 \\
\hline A.3 Older co-resident adults (31-55 years) & 293.8 & 272.9 & 97.5 & 115.7 \\
\hline \multicolumn{5}{|l|}{ B: All co-resident adults age $20-55$ years } \\
\hline B.1: Female recipient(s) only & 180.3 & 185.6 & 83.5 & 85.8 \\
\hline B.2: Male recipient(s) only & 49.4 & 79.8 & 20.9 & 43.3 \\
\hline B.3: Both male, female recipients & 81.2 & 77.5 & 33.2 & 37.8 \\
\hline
\end{tabular}

Notes: Data are drawn from 1998 Demographic and Health Survey. Dependent variable and sex of respondent are in column heading. Instrumental variable estimate in each cell in panels A and B is coefficient on indicator of whether a pension recipient resides in the household. Regressions also control for respondent's age, household age and sex composition, and wealth. In panel A, there is one instrument for pension receipt—an indicator for whether any household member is age-eligible for the pension. In panel B, there are three instrumentsindicators for whether there is at least one age-eligible woman, at least one age-eligible man, or age-eligibles of both genders. Jackknife standard errors (in square brackets) in panels A and B are robust to arbitrary forms of heteroskedasticity and take into account clustering at the household level. 
Table 3. Years of education of children and presence of a pension recipient in the household

\begin{tabular}{lcccccccccc}
\hline & \multicolumn{3}{c}{ Ages 6-14 } & \multicolumn{3}{c}{ Ages 6-12 } & \multicolumn{3}{c}{ Ages 13-14 } \\
& Boys & Girls & $\Delta$ & Boys & Girls & $\Delta$ & Boys & Girls & $\Delta$ \\
\hline & -0.36 & -0.08 & 0.28 & -0.41 & 0.07 & 0.48 & -0.27 & -0.44 & -0.27 \\
$\begin{array}{l}\text { A. Child co-resides with } \\
\text { pensioner }\end{array}$ & {$[0.12]$} & {$[0.15]$} & {$[0.19]$} & {$[0.15]$} & {$[0.16]$} & {$[0.20]$} & {$[0.32]$} & {$[0.30]$} & {$[0.32]$} \\
\hline
\end{tabular}

B. Child co-resides with:

\begin{tabular}{lcccccc} 
Pensioner & -0.21 & 0.02 & -0.30 & 0.16 & -0.11 & -0.30 \\
& {$[0.17]$} & {$[0.17]$} & {$[0.17]$} & {$[0.18]$} & {$[0.35]$} & {$[0.34]$} \\
\multirow{2}{*}{ Mother } & 0.09 & 0.14 & & & & \\
& {$[0.07]$} & {$[0.07]$} & 0.09 & 0.16 & 0.06 & 0.16 \\
& & & {$[0.07]$} & {$[0.07]$} & {$[0.16]$} & {$[0.15]$} \\
\multirow{2}{*}{ Pensioner and mother } & -0.34 & -0.19 & -0.25 & -0.14 & -0.52 & -0.28 \\
& {$[0.14]$} & {$[0.13]$} & {$[0.13]$} & {$[0.13]$} & {$[0.34]$} & {$[0.29]$} \\
\hline
\end{tabular}

Notes: Data are drawn from the 1998 Demographic and Health Survey. Instrumental variable estimate in each cell is coefficient on indicator of whether pension recipient is resident in the household (in panel A) and also whether mother is present in household and interaction between those two indicator variables (in panel B). Instruments are pension eligibility (in panel A) and also pension eligibility interacted with presence of mother in household (in panel B). Regressions also control for child's year of age, household composition (number of residents in each of 10 age and sex specific groups) and wealth. Jackknife standard errors (in square brackets) are robust to arbitrary forms of heteroskedasticity and take into account clustering at the household level. 
Appendix Table 1: Estimates of $p$-values taking into account multiple hypothesis tests

\begin{tabular}{|c|c|c|c|c|c|c|}
\hline \multirow{2}{*}{$\begin{array}{l}\text { Dependent } \\
\text { Variable }\end{array}$} & \multirow{2}{*}{$\begin{array}{l}\text { Age } \\
\text { Group }\end{array}$} & \multirow{2}{*}{$\begin{array}{c}\text { IV coefficient } \\
\text { estimate } \\
\text { (from Table 2) } \\
{[1]} \\
\end{array}$} & \multirow{2}{*}{$\begin{array}{c}\text { Absolute value } \\
\text { of asymptotic } \\
\text { Z-test statistic } \\
{[2]} \\
{\left[\begin{array}{c}{[2]} \\
\end{array}\right.}\end{array}$} & \multicolumn{3}{|c|}{$\begin{array}{l}\text { Resampling-based } p \text {-values, using alternative approaches to } \\
\text { adjust for multiple hypotheses }\end{array}$} \\
\hline & & & & $\begin{array}{c}\text { No adjustment } \\
{[3]}\end{array}$ & $\begin{array}{c}\text { Sex-Specific } \\
\text { Group Error Rate } \\
{[4]}\end{array}$ & $\begin{array}{c}\text { False Discovery } \\
\text { Rate } \\
{[5]} \\
\end{array}$ \\
\hline \multicolumn{7}{|l|}{ MEN } \\
\hline Education & $20-55$ & -1.02 & 2.96 & 0.003 & 0.015 & 0.017 \\
\hline Education & $20-30$ & -1.17 & 2.57 & 0.009 & 0.040 & 0.027 \\
\hline Education & $31-55$ & -0.87 & 1.81 & 0.070 & 0.204 & 0.134 \\
\hline Height & $20-55$ & 0.78 & 0.55 & 0.583 & 0.749 & 0.696 \\
\hline Height & $20-30$ & 1.50 & 0.81 & 0.418 & 0.677 & 0.613 \\
\hline Height & $31-55$ & -0.14 & 0.06 & 0.950 & 0.950 & 0.950 \\
\hline \multicolumn{7}{|l|}{ WOMEN } \\
\hline Education & $20-55$ & -0.47 & 1.47 & 0.141 & 0.278 & 0.179 \\
\hline Education & $20-30$ & -0.85 & 2.23 & 0.026 & 0.107 & 0.073 \\
\hline Education & $31-55$ & -0.19 & 0.49 & 0.690 & 0.684 & 0.683 \\
\hline Height & $20-55$ & -2.76 & 2.36 & 0.019 & 0.084 & 0.073 \\
\hline Height & $20-30$ & -2.09 & 1.41 & 0.158 & 0.278 & 0.179 \\
\hline Height & $31-55$ & -2.86 & 1.61 & 0.108 & 0.278 & 0.179 \\
\hline
\end{tabular}

Notes: IV coefficient estimates (column 1) are from Table 2; test-statistics for the null hypothesis of no effect are based on the standard errors reported in table 2. Columns 3-5 report p-values based on re-sampling. Column 3 does not take into account multiple testing. The p-value in each row of column 3 is the fraction of times the test statistic in the resample exceeds the absolute value of the test statistic in column 2. Column 4 calculates the sex-specific group error rate (or, more generally, the family wise error rate, FWER, for the family of hypotheses which are, in our case, the 6 sex-specific models). Column 5 controls the False Discovery Rate (FDR) within each sex-specific group of 6 hypotheses to adjust for multiple testing. This is a less conservative and more powerful approach than controlling the FWER. Each p-value is based on 50,000 replicates. In each replicate, pension eligibility and pension receipt is randomly assigned to households so that the null hypothesis of no effect is known to be true. The first stage models are unaffected. 